\title{
Overheating risk evaluation of school classrooms
}

\author{
Despoina Teli ${ }^{1, *}$, Mark F. Jentsch ${ }^{1}$, Patrick A.B. James ${ }^{1}$, AbuBakr S. Bahaj ${ }^{1}$ \\ ${ }^{1}$ Sustainable Energy Research Group, School of Civil Engineering and the Environment, University of \\ Southampton, Southampton SO17 1BJ, United Kingdom \\ * Corresponding author. Tel: +44 (0)2380592134,E-mail: dt1e09@soton.ac.uk
}

\begin{abstract}
This paper presents a pilot study which considers the overheating risk of classrooms in school buildings. Four schools in Southampton in the South of the UK, constructed during the period of the 1950s1980s were used as case study examples. The schools were studied in terms of the parameters or the combination of parameters that may drive classroom overheating. Topographic features, built-up area, urban density, adjacency to roads and parks and other characteristics such as building form and materials were assessed, looking at the urban, building and classroom scale. In addition to this a questionnaire survey was conducted to assess the teachers' perception of their classrooms' thermal environment. The survey responses are discussed and compared to the outcomes of the school parameter analysis, also considering the limitations of the survey approach. It was found that gaining an understanding of the occupants' perception of the thermal conditions in a school's classrooms is essential for developing recommendations for addressing overheating. The study appears to indicate that individual perception of overheating may outweigh the objective influence of urban design and construction parameters on the indoor thermal conditions.
\end{abstract}

Keywords: School buildings, Overheating, Microclimate, Refurbishment, Classroom.

\section{Introduction}

Over recent years, children and teachers in the UK have been experiencing uncomfortably warm thermal conditions inside school classrooms during non-heating periods [1]. This potentially has implications on learning outcomes since it has long been understood that an increase in the indoor temperature may lead to a decline in the productivity of students [2].

Some school buildings constructed between the 1950s and the 1980s are unsuitable for hot summer periods, due to characteristics such as low thermal mass and highly glazed facades. Building performance simulations of typical UK school building types have shown that their overheating risk is likely to be exacerbated under the predicted future climates [3]. Due to cuts in public budgets new school projects have been cancelled in the UK [4] and the life of the majority of the existing school building stock will have to be extended further. In terms of internal thermal comfort, summer overheating could be addressed by installing air conditioning systems, a solution which has been widely adopted in southern Europe over the past decades [5]. The adaptation of such a measure would however conflict with the goal to reduce building related greenhouse gas emissions [6]. It would also set a precedent where airconditioning would become the expected norm.

The aim of this study is to investigate methodological approaches for evaluating the overheating risk of school buildings. It considers the schools' characteristics and the teachers' perception of their classroom's thermal conditions.

\section{Parameters that drive overheating}

The thermal conditions inside a building are determined by the interactions between the external climate and the building, the building shell and the internal space and the internal space and the occupants [7]. Accordingly, the parameters which influence the risk of overheating in buildings are: 
- $\quad$ The external climatic conditions, i.e. the air temperature; solar radiation; rainfall; relative humidity and wind velocity.

- The microclimatic profile, i.e the local scale climate which is affected by the surrounding surfaces (albedo, thermal capacity); topography; vegetation; soil structure and urban form (industrial processes, transportation, buildings, human metabolism) [8].

- The building shape and form, i.e. the geometric relations (envelope area to volume ratio, building height) which determine the building's exposure to solar radiation and the ambient air [9].

- The building fabric properties, i.e. the thermo-physical properties of its construction materials (U-values, g-values and albedo, thermal capacity).

- Internal gains, i.e. the sensible and latent heat emitted by human bodies, lighting, computing and office equipment, electric motors and appliances [10].

During the last 30 years, there has been a trend towards warmer summers [11]. This trend is likely to continue as projections for the future UK climate in the 2020s, under a medium emissions scenario, predict about $1.5{ }^{\circ} \mathrm{C}$ higher summer mean temperatures and up to $3{ }^{\circ} \mathrm{C}$ higher summer mean daily maximum temperatures, relative to a modelled 1961-1990 baseline period [12]. This can be expected to further drive the occurrence of summer overheating in buildings.

\section{Methodology for overheating risk assessment}

Four primary schools in Southampton on the South coast of the UK were chosen as case study examples in order to evaluate overheating risks of existing school buildings. Primary schools were selected as the teachers and students remain in the same classroom during the school hours ensuring uniformity in terms of occupancy. The study consisted of two components: (i) an aerial photo analysis of the schools and their surrounding environment and (ii) a questionnaire survey of the teachers.

\subsection{Aerial-photo analysis}

The aerial photo analysis, which is highlighted in Fig.1 for three of the schools discussed in this paper, included:

- the surrounding urban environment (urban density level, building heights, adjacency to roads/parks/fields/water).

- the school ground (density level, greenery/hard surfaces, location of the building within the school ground, shape of the school ground in relation to the orientation)

- the building (form, shape, roof cover)

- the classrooms (materials, window/wall ratio, shading conditions)

The area within $100 \mathrm{~m}$ around the schools was studied since the local microclimate of this area was considered as influential for the building performance.

\subsection{Questionnaire survey}

The teachers of the 4 schools were requested to complete an 11 question survey investigating their perception of their individual classroom's thermal environment. In case they had been in that classroom for less than 1 year, they were asked to answer for their previous classroom (within the same school). Most of the questions were closed type questions (fixed-response). The survey forms were filled in face-to-face with the respondents in an interview style. The aim of the questionnaire was to identify the following: 
- when, where and under which circumstances overheating occurs

- the duration of overheating occurrences in the school/classroom

- the teachers' understanding of the factors which cause overheating

- the mitigation measures taken to date with respect to overheating

- the teachers' perceived impact of overheating on students

The pilot study of four schools has highlighted limitations of the survey which need to be taken into account in the analysis of the results. These limitations are:

- the subjective perception of individuals

- the possibility of an established view in each school about the thermal conditions in the classrooms

- the expectations of individuals based on their perception of the outside climatic alterations throughout the year.

\section{Aerial photo analysis of the four investigated schools}

The four schools used in this study are denoted as A, B, C and D in Fig.1. They share their school grounds in pairs and are surrounded by residential areas of a relatively low density with detached 2-storey houses. The schools are not shaded by surrounding buildings or trees. Vegetation is limited to grass surfaces with few trees in the school grounds. The outdoor space material surrounding the buildings is mainly tarmac, covering 58 and $68 \%$ of the open spaces for schools A, B and C,D respectively (excluding sports fields).

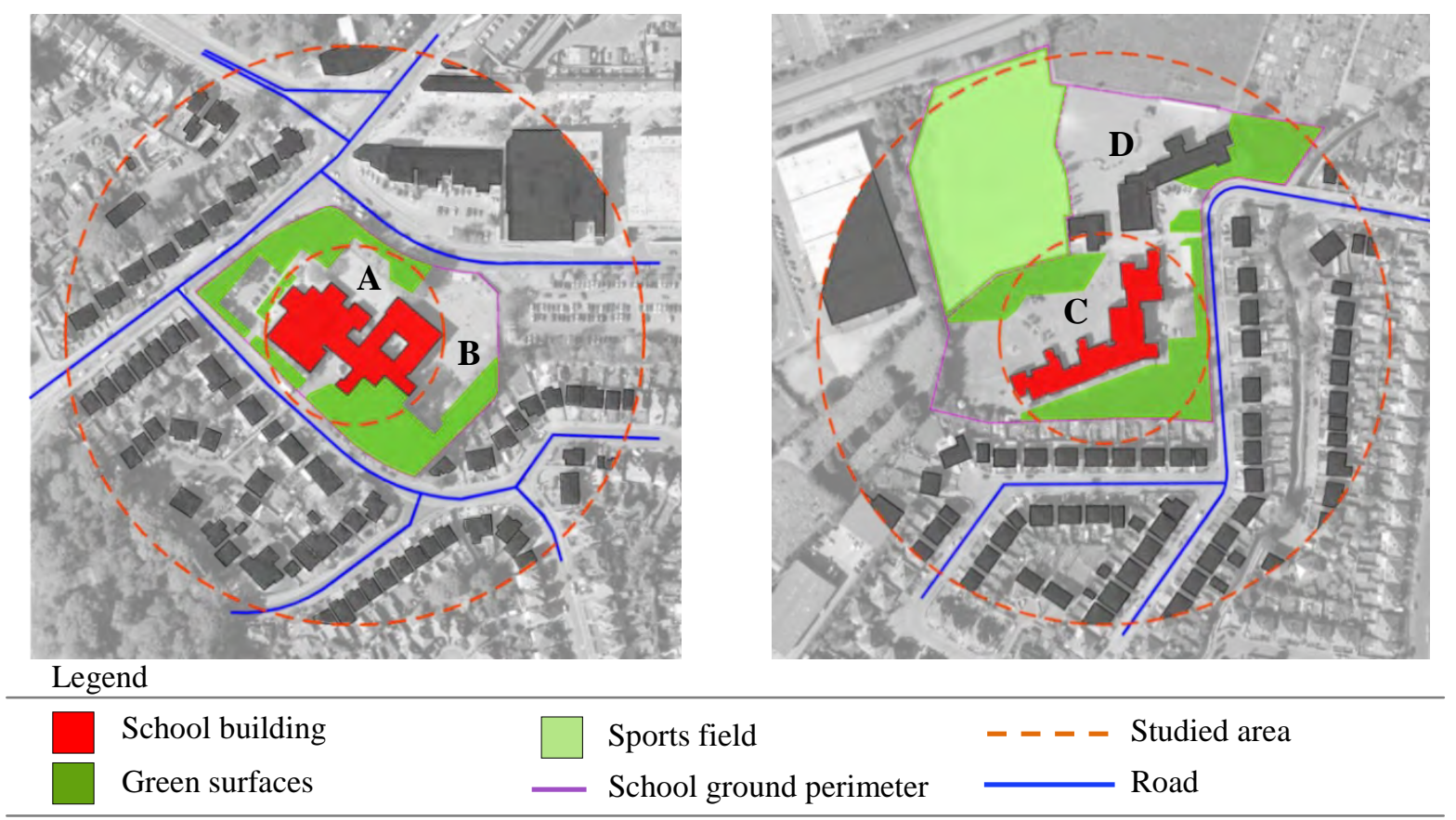

Fig. 1. Analysis of the main urban characteristics of three of the studied schools

School A is a compact one-storey building with an assembly hall in the centre and the classrooms located around it. School B consists of two parts which create an enclosed yard, a 2-storey L shaped building housing the classrooms and a 1-storey building with the remaining school spaces. Schools C and D both consist of linear sections. The building parts which face southeast (SE) accommodate the classrooms. In school D the classroom part has 2 storeys. 
Schools A and B were built in 1978 using a light-weight construction with steel frames and pre-fabricated concrete panels. The other two schools (C and D) were constructed in 1950 using a brick cavity wall system. 40 to $60 \%$ of the façades are glazed in all four schools (Fig.2). Windows in schools $\mathrm{A}$ and $\mathrm{B}$ are single glazed whilst they are double glazed in schools C and D. All buildings are internally shaded with blinds or curtains. In schools $C$ and D most classrooms face SE while in school A most classrooms open to two orientations and in school B half of the classrooms face northeast (NE) and half southeast (SE). This is shown in Fig.3.
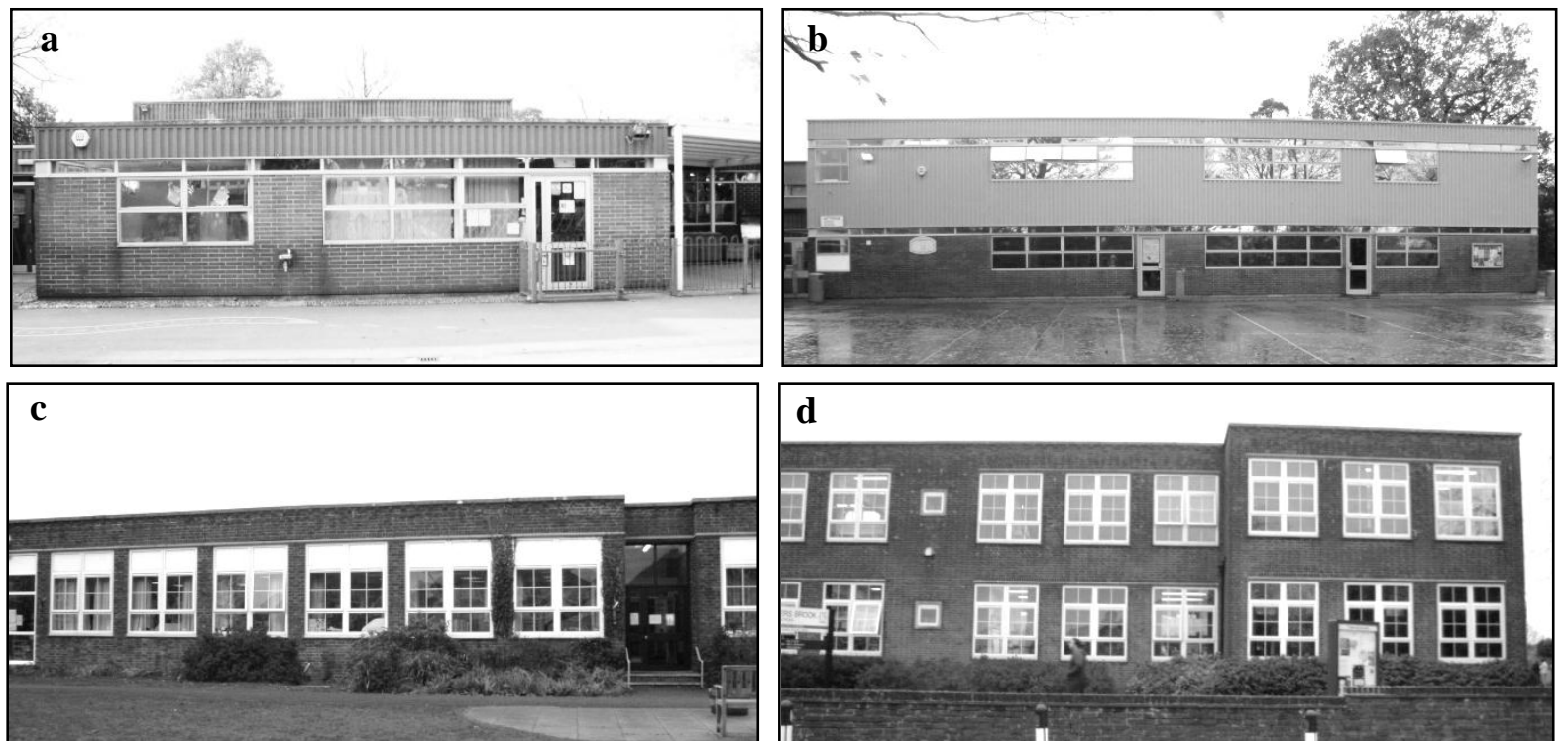

Fig. 2. Schools' facades: a. Northeast elevation of school A, b. Southeast elevation of school B, $c$. Southeast elevation of school C and d. Southeast elevation of school D.

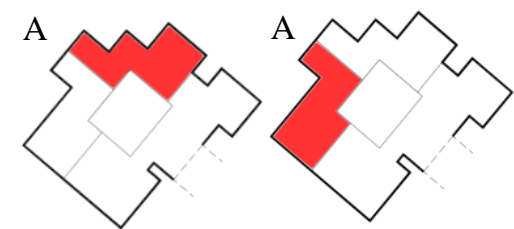

1

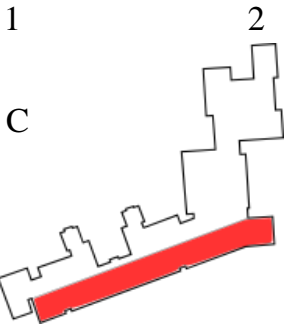

7

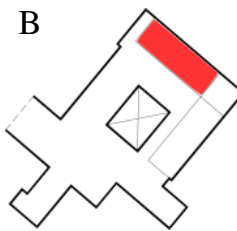

3

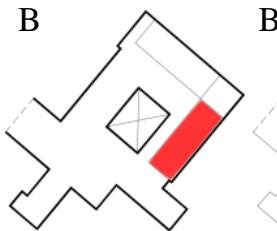

4

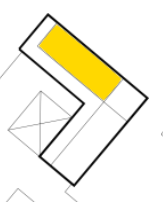

5
B

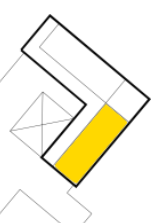

6

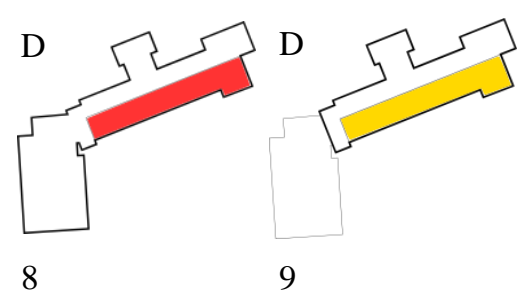

\begin{tabular}{l} 
Legend \\
\hline$\square$ Classrooms on ground floor \\
$\square$ Classrooms on $1^{\text {st }}$ floor
\end{tabular}

Fig. 3. Classroom clusters of the case study schools

From the aerial photo analysis 9 classroom clusters were identified based on construction, orientation, storey and surrounding environment (Fig.3). Clusters 5 and 6 (school B) appear to have the highest potential risk of overheating. Their NE and SE orientation in combination with the outdoor tarmac surfaces, a flat bitumen roof, a light-weight construction, single glazing and a lack of wind exposure are parameters which may drive overheating in the classrooms. Ground floor clusters 3 and 4 have the same characteristics like 5 and 6 apart from the missing heat absorption from the roof. In school A (clusters 1 and 2) the classrooms 
benefit from 2 facades due to the building form which increases their ventilation potential. Cluster 2 is adjacent to a small green area and it is relatively exposed to prevailing SW winds. However, the light-weight construction, single glazing and flat roof indicate a high risk of summer overheating later in the day. Schools C and D (clusters 7-9) benefit from the cavity wall system and double glazing but the large SE oriented windows and the lack of ventilation and shading suggest high penetration of solar radiation.

\section{Questionnaire survey results of the four investigated schools}

50 teachers completed questionnaires across the 4 schools for their individual classroom. Their responses are analysed below and subsequently compared with the outcomes of the aerial photo analysis.

\subsection{Thermal performance of the classrooms}

The teachers were asked to evaluate their classroom's thermal performance for the occupancy period from April to October 2010. As shown in Fig.4, June and July are considered as the months with the greatest overheating occurrence, whilst in May and September are perceived as less problematic, yet with about half of the teachers stating that the classroom is either 'warm' or 'too warm'. April and October are generally perceived as acceptable. It should be noted however that the teachers might be influenced by the general perception of the climatic alterations throughout the year.

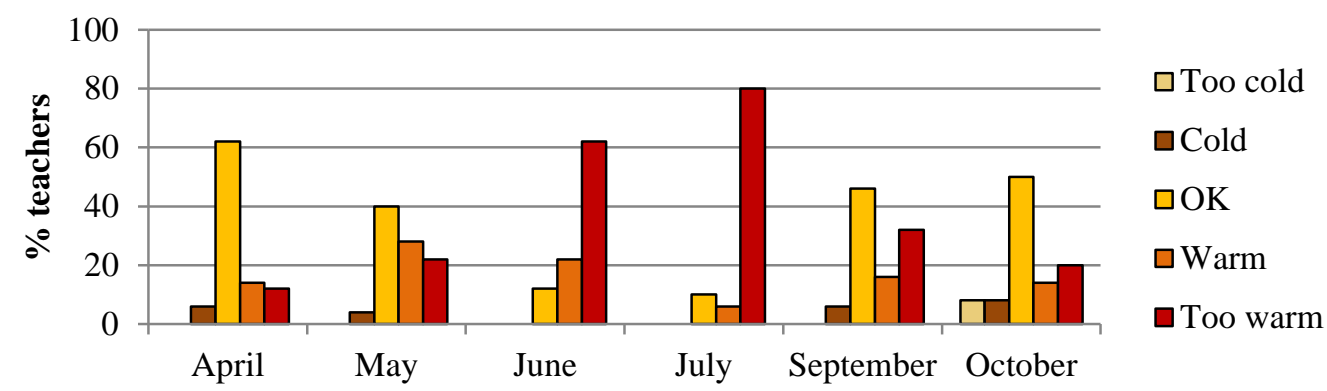

Fig. 4. Perceived classroom temperature conditions from April-October

When comparing individual responses in relation to the clusters described in section 4, a high variation in responses on a single façade orientation was identified for the months of April, May, September and October. In some cases the temperature of adjacent classrooms with exactly the same characteristics was assessed as 'OK' by one respondent and as 'too warm' by another. This suggests that in the spring and autumn months individual variation in perception appears to be more significant for overheating perception than absolute classroom temperatures.

\subsection{Overheating occurrence}

The teachers were asked about the magnitude and duration of overheating in their school and classroom. As shown in Fig.5, 80\% of the teachers stated that in the non-heating season more than $60 \%$ of their school's classrooms experience overheating. In winter the responses vary. One of the reasons for this variation was found to be that in schools A and B the heating system is controllable and some teachers switch it off when temperatures are too high.

Almost $60 \%$ of the respondents answered that overheating occurrences in the non-heating season last for more than a week (Fig.6). For the heating season the responses are less clear. $30 \%$ of the teachers voted for 'not applicable' and about $25 \%$ for 'more than a week'. 


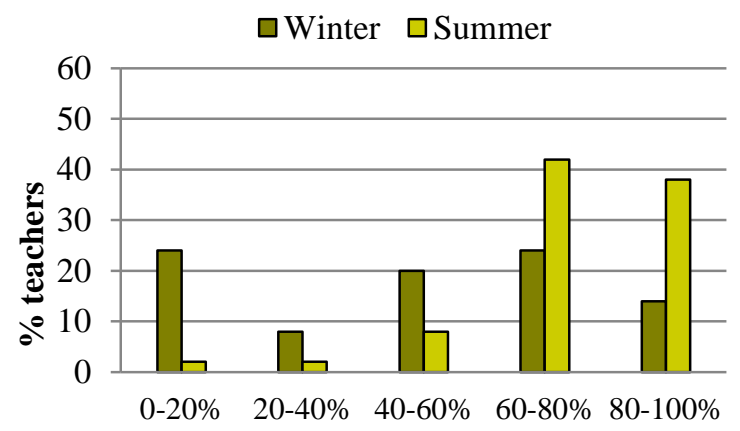

Fig.5. Perceived percentage of the school's classrooms that have experienced overheating

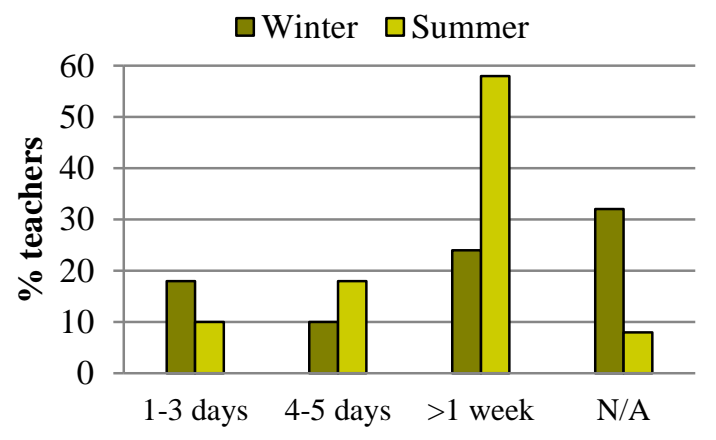

Fig.6. Perceived duration of overheating occurrences in the teachers' classrooms

The teachers were also asked to assess the frequency of overheating occurrences in various school spaces (Fig.7). For the classrooms, $80 \%$ of the teachers agreed that overheating occurs very often while for the assembly hall, circulation areas and library the responses are less pronounced. This difference in perception may be related to the characteristics of the classrooms (high occupancy density, large windows, small window openings, internal gains etc) but it may also be due to the stronger concern of the teachers for the spaces where most of the school activities take place.

Fig. 8 shows the months which are perceived to cause greatest classroom overheating during the school occupancy periods. As expected, June and July were indicated by almost all respondents as the two months with the greatest overheating problems.

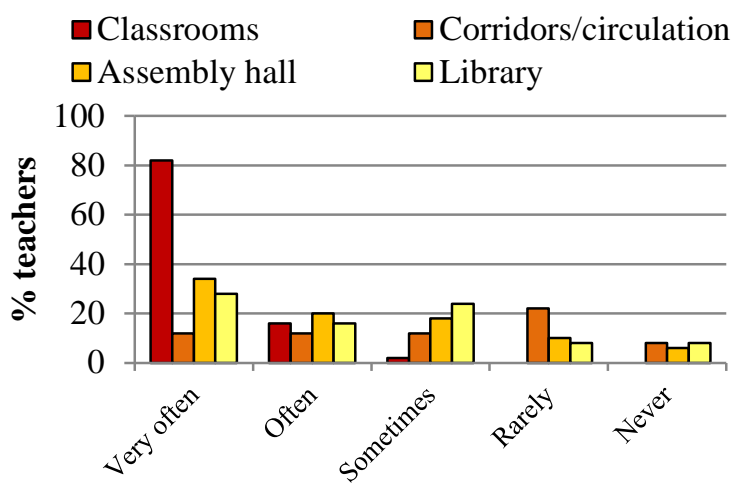

Fig.7. Perceived overheating occurrence in different school spaces

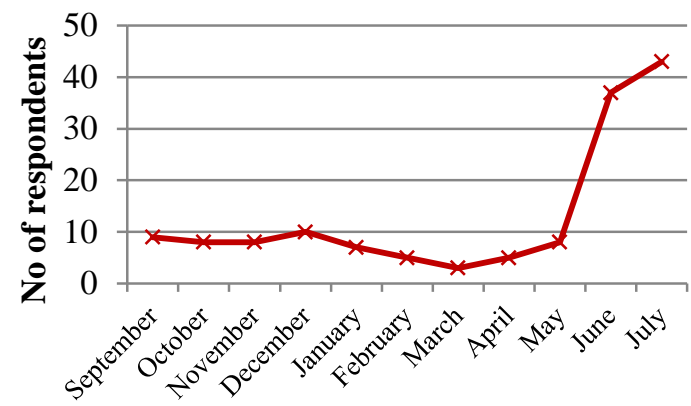

Fig.8. Months perceived to cause greatest overheating (School year: Sept '09-July '10)

\subsection{Possible causes of overheating and mitigation measures applied by the teachers}

In an open question the teachers indicated the factors which they believe to drive overheating in their classroom (Fig.9). Poor ventilation, a poorly controlled heating system and the number of students were the most frequent answers followed by room size and not-openable windows.

Achieving appropriate ventilation is a problem in many classrooms as cross ventilation is not possible. Also, in all 4 schools the windows open only to a certain extent and the internal shading obstructs the air flow. The heating system was often highlighted as an issue because some teachers cannot control it in their classroom or they weren't aware that they could. 
The students' habits and behaviour towards heat stress were identified as a point of concern. According to some teachers, children may be clearly too warm and yet do not take off their jumpers or ask for help. Teachers felt that children's perception of heat is different from adults and that this should be taken into account when school buildings' thermal conditions are studied. This furthermore indicates that more research is needed addressing the perception of children, looking at temperature thresholds from a children's perspective and the implications of classroom overheating for their learning experience.

Fig.10 shows the measures taken by the teachers when overheating occurs. The question was fixed-response with the opportunity to add further measures. All teachers selected window opening and almost everyone drinking of water.

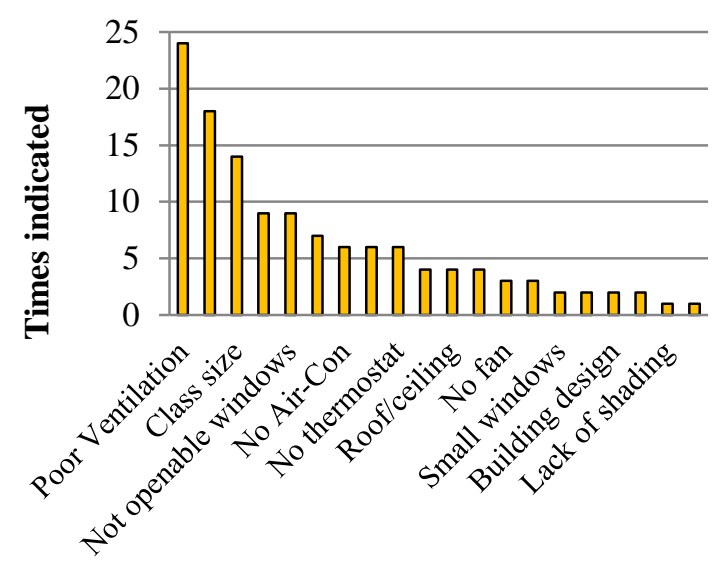

Fig. 9. Causes for overheating of their classroom according to teachers' responses

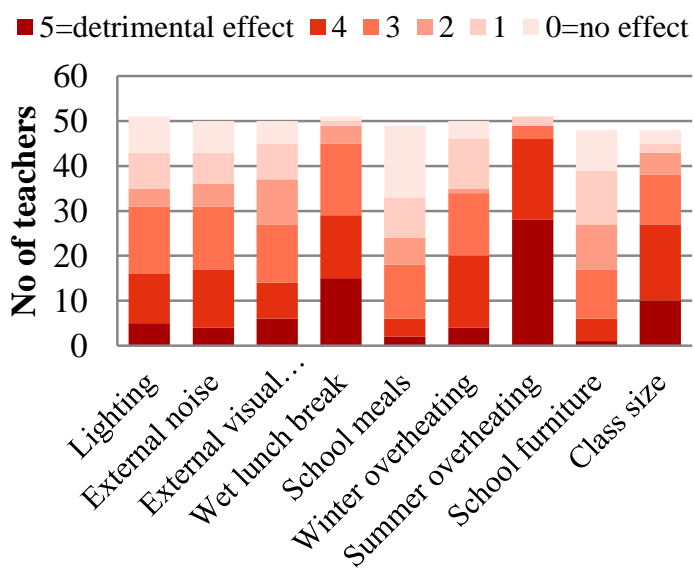

Fig. 11. Perceived effect of different factors on students' learning experience

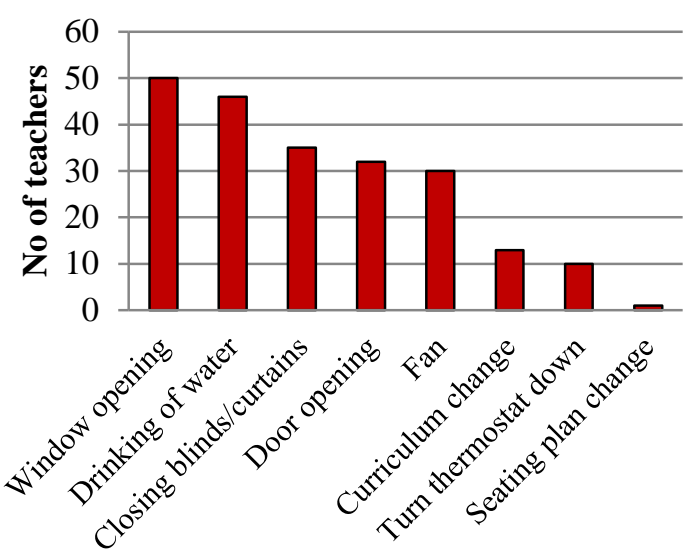

Fig. 10. Mitigation measures taken by teachers when overheating occurs

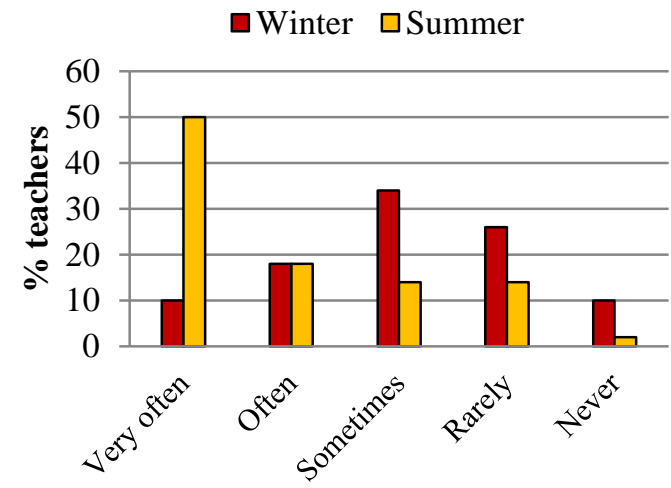

Fig. 12. Complains from children about excessively high temperatures in classroom

\subsection{Impact on students}

The teachers were asked to rate 9 factors in terms of their impact on students' learning experience, using a scale of $0-5,0$ representing no impact and 5 standing for a highly detrimental impact. As shown in Fig.11, summer overheating gathered the largest number of 5 and 4 rates. This is followed by a wet lunch break and the class size (number of occupants in classroom). However, it should be taken into account that this result may have been affected by the specific interest of the survey in summer overheating. 
Teachers were also asked whether students have complained about excessively high temperatures (Fig.12). 50\% of them said that this was 'very often' the case during the nonheating season and some noted that children may not complain even though they feel discomfort.

\section{Discussion}

This work investigated the overheating risk of four UK schools through an aerial photo analysis and a questionnaire survey of the schools' teachers. The aerial photo analysis suggested a high overheating risk within all 4 schools which was verified by the teachers' survey responses. However, a detailed comparison at the classroom level showed variations in individual responses for the spring and autumn months. This appears to indicate that the individual perception of thermal comfort may outweigh the impacts of the building's design and its surrounding landscape conditions on indoor temperatures. The teachers' observations that children may have a different thermal perception to adults suggest that more work is needed looking at the relation between children's perception and building overheating.

The study furthermore highlighted that teachers are often not aware of how their classroom operates (widow opening, heating system). Therefore, low-cost measures such as training may be an effective way to address hot classroom conditions and should be explored prior to taking any retrofitting measures.

\section{References}

[1] NASUWT, Safe to Teach? Health and Safety at Work, Birmingham, 2008.

[2] D. P. Wyon, Studies of Children under Imposed Noise and Heat Stress, Ergonomics 13, 1970, pp 598 - 612.

[3] D. P. Jenkins, A. D. Peacock, \& P. F. G. Banfill, Will future low-carbon schools in the UK have an overheating problem?, Building and Environment, 44, 2009, pp 490-501.

[4] Hansard Parliamentary Debates, Vol. 513, col. 47, 5 July 2010.

[5] M. Santamouris, \& D. Asimakopoulos, Passive cooling of buildings, James \& James, London, 1996.

[6] UK-Parliament, Climate Change Act, The Stationery Office Limited, 2008.

[7] T.R. Oke, Boundary layer climates, Methuen, London, 1987.

[8] F. S. De La Flor, \& S. A. Domínguez, Modelling microclimate in urban environments and assessing its influence on the performance of surrounding buildings. Energy and Buildings, 36, 2004, pp 403-413.

[9] B. Givoni, Climate considerations in building and urban design, Van Nostrand Reinhold, New York, 1998.

[10]CIBSE, Guide A-Environmental design, Chartered Institution of Building Services Engineers, London, 2006.

[11]G. J. Jenkins, M.C. Perry, M.J. Prior, The climate of the United Kingdom and recent trends, Exeter UK: Met Office Hadley Centre, 2008.

[12]G. J. Jenkins, J. M. Murphy, D. M. H. Sexton, J. A. Lowe, P. Jones \& C. G. Kilsby, UK Climate Projections: Briefing report. Exeter, UK: Met Office Hadley Centre, 2009. 